\title{
QUALIDADE DOS FRUTOS DE GOIABEIRAS SUBMETIDAS À PODA E APLICAÇÃO DE NITRATO DE POTÁSSIO
}

Juliana Aparecida dos Santos ${ }^{1}$, Flávia Aparecida de Carvalho Mariano Nasser ${ }^{2}$, Maurício Dominguez Nasser ${ }^{3}$

\footnotetext{
${ }^{1}$ Mestre em Agronomia e Docente na ETEC Andradina (SP).

${ }^{2}$ Pós-Doutoranda em Horticultura na UNESP - Botucatu (SP).

${ }^{3}$ Doutorando em Horticultura na UNESP - Botucatu (SP), Pesquisador Científico - Polo Regional Alta Paulista/APTA.
}

RESUMO: Considerando a importância da poda e a falta de informações sobre a utilização de adubação foliar com nitrogênio e potássio na cultura da goiabeira (Psidium guajava L.) objetivou-se avaliar o efeito da aplicação de nitrato de potássio $\left(\mathrm{KNO}_{3}\right)$ após a poda de frutificação em goiabeira, sobre a qualidade dos frutos das cultivares Paluma, Pedro Sato, Sassaoka e Século XXI. O delineamento experimental utilizado foi o de blocos casualizados com três repetições, uma planta por parcela, empregando-se o esquema fatorial $2 \times 4$, sendo duas doses $(0$ e $4 \%$ ) e quatro cultivares de goiabeira. Os tratamentos foram: T1N1 (cv. Paluma com $\mathrm{KNO}_{3}$ ); T1N0 (cv. Paluma sem $\mathrm{KNO}_{3}$ ); T2N1 (cv. Pedro Sato com $\mathrm{KNO}_{3}$ ); T2N0 (cv. Pedro Sato sem $\mathrm{KNO}_{3}$ ); T3N1 (cv. Sassaoka com $\mathrm{KNO}_{3}$ ); T3NO (cv. Sassaoka sem $\mathrm{KNO}_{3}$ ); T4N1 (cv. Século XXI com $\mathrm{KNO}_{3}$ ) e T4N0 (cv. Século XXI sem $\mathrm{KNO}_{3}$ ). Nas condições deste experimento, conclui-se que a massa, o diâmetro longitudinal e transversal dos frutos e os valores para sólidos solúveis (SS), acidez titulável (AT) e o índice de maturação (relação SS/AT) não foram alterados com a aplicação de nitrato de potássio após a poda de frutificação para as cultivares estudadas.

Palavras-chave: Psidium guajava L. Qualidade. Nitrato de potássio.

\section{QUALITY OF GUAVA FRUIT SUBMITTED TO PRUNING AND APPLICATION OF POTASSIUM NITRATE}

\begin{abstract}
Considering the importance of pruning and lack of information on the use of foliar fertilization with nitrogen and potassium in the culture of guava (Psidium guajava $\mathrm{L}$.) the objective of this study to evaluate the effect of potassium nitrate $\left(\mathrm{KNO}_{3}\right)$ application after fruit pruning on the physico-chemical quality of the fruits of guava cultivars Paluma, Pedro Sato, Sassaoka and Seculo XXI. The experimental design used was the randomized block with three replications, one plant per plot, using a $2 \times 4$ factorial design, with two doses of potassium nitrate $(0$ and $4 \%)$ and four guava cultivars. The treatments were: T1N1 (cv. Paluma with $\mathrm{KNO}_{3}$ ); T1NO (cv. Paluma without $\mathrm{KNO}_{3}$ ); T2N1 (cv. Pedro Sato with $\mathrm{KNO}_{3}$ ); T2N0 (cv. Pedro Sato without $\mathrm{KNO}_{3}$ ); T3N1 (cv. Sassaoka with $\mathrm{KNO}_{3}$ ); T3N0 (cv. Sassaoka without $\mathrm{KNO}_{3}$ ); T4N1 (cv. Século XXI with $\mathrm{KNO}_{3}$ ) e T4N0 (cv. Século XXI without $\mathrm{KNO}_{3}$ ). The mass, the longitudinal and transverse diameter of the fruits and the total amount of soluble solids, the titratable acidity and the ratio (SS/AT) also did not change with the application of
\end{abstract}

Cultura Agronômica, Ilha Solteira, v.24, n.4, p.271-280, 2015 
potassium nitrate pruning after fruiting for the cultivars.

Key words: Psidium guajava L. Quality. Potassium nitrate.

\section{INTRODUÇÃO}

Segundo Medina (1988), a goiabeira tem origem na região tropical do continente americano, sendo seu provável centro de origem a região compreendida entre o sul do México e o norte da América do Sul. Esta cultura encontra-se difundida por todas as regiões tropicais e subtropicais do mundo. A cultura da goiabeira produz em praticamente todo o território brasileiro e em quase todo o tipo de clima e solo (MANICA et al., 2000).

A goiabeira possui grande importância econômica para o Brasil, sendo cultivada em quase todas as regiões desde o Rio Grande do Sul até o Maranhão, destacando-se na região Sudeste os estados de São Paulo, Minas Gerais e Rio de Janeiro; Nordeste, Pernambuco, Bahia e Paraíba; Centro-Oeste, Goiás; Sul, Rio Grande do Sul e Paraná (PESSOA et al., 2009).

De acordo com Manica et al. (2000), entre as frutas tropicais, a goiaba se destaca por possuir excelente qualidade, atribuída ao elevado valor nutritivo, sendo uma das melhores fontes de vitamina $\mathrm{C}$, com valores seis a sete vezes superiores aos dos frutos cítricos, perdendo apenas para acerola (Malpighia emarginata D.C.), camu-camu (Myrciaria dubia H. B. K. (McVough) e caju (Anacardium occidentale L.).

Caldeira (1989) utilizando nitratos em mangueira considerou que, a síntese de etileno na planta poderia decorrer da redução do nitrato à metionina ou do estresse físico-químico provocado pelas altas concentrações de nitrato. Em trabalhos com indução de florescimento, Barros et al. (1998) conseguiram com sucesso induzir o florescimento da mangueira com aplicações de $\mathrm{KNO}_{3}$. No entanto, alguns pesquisadores como Valente e Donadio (1993) e Pal et al. (1984) não obtiveram resultados satisfatórios no uso desta técnica.

Segundo Silva et al. (2006), o nitrogênio e o potássio são nutrientes que podem influenciar diretamente na qualidade dos frutos, e o excesso de nitrogênio reduz o valor de sólidos solúveis no suco dos frutos. Porém, no geral, a adição elevada de potássio aumenta o teor de sólidos solúveis, podendo-se inferir que a qualidade dos frutos está relacionada com doses de nitrogênio e potássio aplicados na fertilização (ARAÚJO, 2001).

Objetivou-se com o presente trabalho estudar o efeito da aplicação de nitrato de potássio $\left(\mathrm{KNO}_{3}\right)$ após a poda de frutificação em goiabeira, sobre a qualidade dos frutos das cultivares Paluma, Pedro Sato, Sassaoka e Século XXI.

\section{MATERIAL E MÉTODOS}

O experimento foi realizado no Laboratório de Tecnologia de Alimentos da Universidade Estadual Paulista/UNESP, Campus de Ilha Solteira. 
Os frutos das cultivares de goiabeiras Paluma, Pedro Sato, Sassaoka e Século XXI utilizados no experimento foram produzidos na Fazenda Ensino, Pesquisa e Extensão, Campus de Ilha Solteira (FEPE). O solo da fazenda é classificado como Latossolo Vermelho distrófico típico, com textura argilosa segundo o Sistema Brasileiro de Classificação de Solos (EMBRAPA, 2006). A FEPE está localizada no município de Selvíria-MS, com latitude $20^{\circ}$ $25^{\prime} \mathrm{S}$ e longitude $51^{\circ} 21^{\circ} \mathrm{O}$. O clima da região é Aw, segundo a classificação de KOPPEN, apresentando temperatura média anual de $25^{\circ} \mathrm{C}$ e precipitação anual de $1300 \mathrm{~mm}$ (CENTURION, 1982).

As goiabeiras apresentavam 7 anos de idade, plantas propagadas por estaquia, conduzidas em forma de copa aberta e irrigadas por microaspersão. O espaçamento de plantio adotado foi $8 \mathrm{~m}$ entre linhas e $6 \mathrm{~m}$ entre plantas. Foi realizada adubação de produção seguindo as recomendações do Boletim Técnico 100 do Instituto Agronômico de Campinas (RAIJ et al., 1996).

Foram necessárias pulverizações para o controle químico de psilídeo (Triozoida sp.) com inseticida do grupo químico dos neonicotinoides (i.a. imidacloprid), e de forma preventiva utilizou-se fungicida cúprico para a bacteriose (Erwinia psidii).

Os tratamentos foram: T1N1 (cv. Paluma com $\mathrm{KNO}_{3}$ ); T1N0 (cv. Paluma sem $\mathrm{KNO}_{3}$ ); T2N1 (cv. Pedro Sato com $\mathrm{KNO}_{3}$ ); T2N0 (cv. Pedro Sato sem $\mathrm{KNO}_{3}$ ); T3N1 (cv. Sassaoka com $\mathrm{KNO}_{3}$ ); T3N0 (cv. Sassaoka sem $\mathrm{KNO}_{3}$ ); T4N1 (cv. Século XXI com $\mathrm{KNO}_{3}$ ) e T4N0 (cv. Século XXI sem $\mathrm{KNO}_{3}$ ).

Utilizou-se a intensidade de poda de frutificação média, sendo esta feita deixando cinco pares de folhas por ramo podado a partir da base deste. Todos os ramos de crescimento das plantas foram podados sem se considerar seu diâmetro.

Após a poda de frutificação que foi realizada no dia 10 de março de 2010, foram marcados aleatoriamente 10 ramos por repetição, para cada tratamento. Foram realizadas duas aplicações de Nitrato de Potássio $\left(\mathrm{KNO}_{3}\right)$ a $4 \%$, com auxílio de atomizador manual, no período da manhã, sendo a primeira no dia 11 de março de 2010 e a segunda aplicação 30 dias após. Foi realizado a desbrota dos ramos vegetativos em todas as plantas e o desbastes dos frutos, deixando-se até 2 frutos por ramo produtivo.

A colheita dos frutos foi realizada entre 196 e 244 dias após a poda de frutificação, dependendo da cultivar. Foram colhidos todos os frutos das cultivares de goiabeira Paluma, Pedro Sato, Sassaoka e Século XXI em ponto de colheita, sendo que a cultivar Sassaoka juntamente com a cultivar Século XXI foram as primeiras a entrar em ponto de colheita, seguidas das cultivares Pedro Sato e Paluma, respectivamente.

Separadamente os frutos das cultivares de goiabeiras estudadas, foram colhidos e levados em sacos de polietileno, acondicionados em caixa plástica ao Laboratório de Tecnologia de Alimentos da UNESP de Ilha Solteira. Foram utilizadas amostras de 5 goiabas para cada tratamento para a realização das análises, para as seguintes determinações:

a) Massa média dos frutos, em gramas (g), determinado com auxílio de uma balança digital;

Cultura Agronômica, Ilha Solteira, v.24, n.4, p.271-280, 2015 
b) Diâmetro longitudinal e transversal dos frutos, com auxílio de paquímetro, sendo os resultados expressos em centímetros $(\mathrm{cm})$.

c) Os teores de sólidos solúveis (SS), a acidez titulável (AT) e a razão SS/AT (índice de maturação) foram determinados a partir de 3 análises para cada tratamento, utilizando-se amostras compostas de 5 frutos de cada cultivar de goiabeira, com 2 repetições cada.

- O teor de sólidos solúveis (SS) foi determinado por refratometria, transferindo-se uma gota de suco da fruta para o prisma do Refratômetro de Abb e Carl Zeiss e efetuando-se a leitura, com correção de temperatura para $20^{\circ} \mathrm{C}$ e expresso em ${ }^{\circ}$ Brix (INSTITUTO ADOLFO LUTZ, 1985);

- A acidez titulável (AT) foi determinada por titulometria, com diluição de $10 \mathrm{~mL}$ de suco, obtido com auxílio de centrífuga, em $40 \mathrm{~mL}$ de água destilada, 4 gotas de azul de bromotimol e titulação com solução de $\mathrm{NaOH} 0,05 \mathrm{~N}$, até a amostra atingir coloração arroxeada. O cálculo de acidez foi realizado segundo as Normas Analíticas do Instituto Adolfo Lutz (1985), expressando-se o resultado em gramas de ácido cítrico por $100 \mathrm{~mL}$ de amostra;

- O índice de maturação (relação SS/AT) foi obtido pela razão entre o teor de sólidos solúveis (SS) e da acidez titulável (AT).

O delineamento experimental utilizado foi o de blocos casualizados com três repetições, uma planta por parcela, empregando-se o esquema fatorial $2 \times 4$, sendo duas doses $(0$ e $4 \%)$ e quatro cultivares de goiabeira.

Na análise estatística foi utilizado o teste de Tukey, ao nível de 5\% de probabilidade. As análises foram feitas com auxílio do programa estatístico computacional SISVAR (FERREIRA, 2011).

\section{RESULTADOS E DISCUSSÃO}

Observou-se que não ocorreu diferença estatística significativa para a aplicação de nitrato de potássio para a massa, diâmetro longitudinal e transversal dos frutos (Tabela 1). Entretanto ocorreu diferença estatística significativa entre as cultivares, ao nível de 1\% para massa e diâmetro longitudinal e ao nível de 5\% para o diâmetro transversal, porém não ocorreu interação entre os fatores nitrato de potássio e cultivar, ou seja, estes fatores são independentes.

A aplicação de $\mathrm{KNO}_{3}$ associada à poda de frutificação não mostrou ser eficiente no aumento da massa, diâmetros longitudinal e transversal comparativamente à realização apenas da poda. Chatzivagiannis (2008) relatou que a aplicação de Paclobutrazol (PBZ) não afeta as qualidades físico-químicas dos frutos de mangueiras ( $M$. indica) das variedades Bourbon, Palmer e Rosa.

Observou-se que ocorreu diferença estatística entre as cultivares de goiabeiras estudadas, no entanto, a cultivar Século XXI apresentou os menores valores para as variáveis avaliadas, diferindo na massa e diâmetro longitudinal dos frutos das cultivares Paluma, Pedro 
Sato e Sassaoka, porém para a variável diâmetro transversal diferiu apenas da cultivar Paluma (Tabela 2).

Tabela 1. Resumo da análise de variância para o efeito do nitrato de potássio sobre a massa, comprimento e diâmetro dos frutos das cultivares de goiabeira Paluma, Pedro Sato, Sassaoka e Século XXI, submetidas à poda de frutificação associada à aplicação de nitrato de potássio. Ilha Solteira - SP, 2010.

\begin{tabular}{lccc}
\hline Fonte de variação & \multicolumn{3}{c}{ QM } \\
\cline { 2 - 4 } & $(\mathrm{g})$ & $\begin{array}{c}\text { Diâmetro } \\
\text { longitudinal } \\
(\mathrm{cm})\end{array}$ & $\begin{array}{c}\text { Diâmetro } \\
\text { transversal } \\
(\mathrm{cm})\end{array}$ \\
\hline Nitrato de potássio $\left(\mathrm{KNO}_{3}\right)$ & $0,610343^{\mathrm{ns}}$ & $0,001159^{\mathrm{ns}}$ & $0,062833^{\mathrm{ns}}$ \\
Cultivar & $2567,163619^{* *}$ & $2,462247^{* *}$ & $0,511552^{*}$ \\
$\mathrm{KNO}_{3}$ x Cultivar & $431,941122^{\mathrm{ns}}$ & $0,411796^{\mathrm{ns}}$ & $0,111192^{\mathrm{ns}}$ \\
Média geral & 195,6735375 & 8,0850750 & 6,9027333 \\
\hline $\mathrm{CV}(\%)$ & 10,65 & 5,66 & 4,61 \\
\hline$* *$ significativo ao nível de $1 \%$ de probabilidade $(\mathrm{p}<0,01) .{ }^{*}$ significativo ao nível de $5 \%$ de probabilidade \\
$(0,01=<\mathrm{p}<0,05) .{ }^{\mathrm{ns}}$ não significativo $(\mathrm{p}>=0,05)$
\end{tabular}

Tabela 2. Comparação de médias entre as cultivares de goiabeira para massa, diâmetros longitudinal e transversal. Ilha Solteira - SP, 2010.

\begin{tabular}{lccc}
\hline & \multicolumn{3}{c}{ Variáveis } \\
\cline { 2 - 4 } Cultivares & $\begin{array}{c}\text { Massa } \\
(\mathrm{g})\end{array}$ & $\begin{array}{c}\text { Diâmetro } \\
\text { longitudinal } \\
(\mathrm{cm})\end{array}$ & $\begin{array}{c}\text { Diâmetro } \\
\text { transversal } \\
(\mathrm{cm})\end{array}$ \\
\hline Paluma & $204,94 \mathrm{a}^{1}$ & $8,35 \mathrm{a}^{2}$ & $7,17 \mathrm{a}^{3}$ \\
Pedro Sato & $208,29 \mathrm{a}$ & $8,67 \mathrm{a}$ & $7,01 \mathrm{ab}$ \\
Sassaoka & $204,72 \mathrm{a}$ & $8,14 \mathrm{a}$ & $6,95 \mathrm{ab}$ \\
Século XXI & $164,74 \mathrm{~b}$ & $7,18 \mathrm{~b}$ & $6,49 \mathrm{~b}$ \\
\hline
\end{tabular}

${ }_{1,2}$ Médias seguidas da mesma letra na coluna não diferem entre si, pelo teste de Tukey ao nível de $1 \%$ de significância. ${ }^{3}$ Médias seguidas da mesma letra na coluna não diferem entre si, pelo teste de Tukey ao nível de $5 \%$ de significância.

Observou-se que a cultivar Paluma apresentou frutos com maiores dimensões, com massa média de 204,94 g e diâmetros longitudinal e transversal com 8,35 cm e 7,17 cm, respectivamente (Tabela 2). Segundo Pereira (1995), Manica et al. (2000) e Pereira e Nachtigal (2003), a cultivar Paluma pode apresentar frutos grandes com massa superior a 200 $\mathrm{g}$, mesmo em plantas não desbastadas.

A cultivar Pedro Sato também se mostrou com grandes dimensões, sendo que, de acordo com Pereira (1995), Manica et al. (2000) e Pereira e Nachtigal (2003), esta pode atingir massa entre 295 e $407 \mathrm{~g}$ em plantas desbastadas. Assim como as cultivares Paluma e Pedro Sato, a cultivar Sassaoka, apresentou frutos grandes, comparativamente a cultivar Século XXI, podendo ter massa superior a $300 \mathrm{~g}$ (KAVATI, 1997).

A cultivar Século XXI (Tabela 2), produziu frutos pequenos com massa média de $164,74 \mathrm{~g}$ e diâmetros longitudinal e transversal com 7,18 cm e $6,49 \mathrm{~cm}$, respectivamente, 
porém de acordo com Pommer et al. (2006), os frutos desta cultivar podem ter massa média de $200 \mathrm{~g}$.

A massa média do fruto é uma característica importante, sendo que, em geral, os frutos de maior massa são também os de maior tamanho, e estes, por sua vez, são mais atrativos ao consumidor (GONZAGA NETO et al., 1987).

Na Tabela 3, encontram-se descritos os valores da análise de variância para as características de qualidade, onde se observou que não ocorreu diferença estatística significativa para as características de qualidade dos frutos de goiabeira com a aplicação de nitrato de potássio. Porém observou-se diferença estatística significativa ao nível de $1 \%$ entre as cultivares de goiabeira para acidez titulável e a 5\% para a relação SS/AT. Ocorreu ausência de interação nitrato de potássio e cultivar para todas as características de qualidades avaliadas.

Tabela 3. Resumo da análise de variância para o efeito do nitrato de potássio sobre as características de qualidade dos frutos de goiabeira, cultivares Paluma, Pedro Sato, Sassaoka e Século XXI, submetidas à poda de frutificação associada à aplicação de nitrato de potássio. Ilha Solteira - SP, 2010.

\begin{tabular}{lccc}
\hline \multirow{2}{*}{ Fonte de variação } & \multicolumn{3}{c}{ QM } \\
\cline { 2 - 4 } & $\begin{array}{c}\text { Teores de } \\
\text { sólidos solúveis } \\
\left({ }^{\circ} \text { Brix }\right)\end{array}$ & $\begin{array}{c}\text { Acidez titulável } \\
(\mathrm{g} \text { de ác. cítrico/100 } \\
\text { mL de amostra) }\end{array}$ & $\begin{array}{c}\text { Relação } \\
\text { SS/AT }\end{array}$ \\
\hline Nitrato de potássio $\left(\mathrm{KNO}_{3}\right)$ & $0,191852^{\mathrm{ns}}$ & $0,002823^{\mathrm{ns}}$ & $9,916476^{\mathrm{ns}}$ \\
Cultivar & $0,325276^{\mathrm{ns}}$ & $0,040704^{* *}$ & $46,796481^{*}$ \\
$\mathrm{KNO}_{3}$ x Cultivar & $0,230196^{\mathrm{ns}}$ & $0,000035^{\mathrm{ns}}$ & $2,389611^{\mathrm{ns}}$ \\
Média geral & 7,8116333 & 0,4748542 & 16,8997208 \\
\hline $\mathrm{CV}(\%)$ & 9,75 & 7,52 & 13,33 \\
\hline$* *$ significativo ao nível de $1 \%$ de probabilidade $(\mathrm{p}<0,01) .{ }^{*}$ significativo ao nível de 5\% de probabilidade \\
$(0,01=<\mathrm{p}<0,05) .{ }^{\mathrm{n}}$ não significativo $(\mathrm{p}>=0,05)$.
\end{tabular}

Pelo teste de comparação de médias entre as cultivares de goiabeira (Tabela 4), podese observar que ocorreu diferença estatística entre as cultivares para as características químicas acidez titulável e relação SS/AT dos frutos.

Tabela 4. Comparação de médias entre as cultivares de goiabeira para Acidez titulável e Relação SS/AT. Ilha Solteira - SP, 2010.

\begin{tabular}{lcc}
\hline & \multicolumn{2}{c}{ Variáveis } \\
\cline { 2 - 3 } Cultivares & $\begin{array}{c}\text { Acidez titulável } \\
\text { (g de ác. cítrico/100 mL } \\
\text { de amostra) }\end{array}$ & Relação SS/AT \\
\hline Paluma & $0,58 \mathrm{a}^{1}$ & $13,94 \mathrm{c}^{2}$ \\
Pedro Sato & $0,43 \mathrm{bc}$ & $18,18 \mathrm{ab}$ \\
Sassaoka & $0,39 \mathrm{c}$ & $20,15 \mathrm{a}$ \\
SéculoXXI & $0,49 \mathrm{~b}$ & $15,33 \mathrm{bc}$ \\
\hline${ }^{1}$ Médias seguidas da mesma letra na coluna não diferem entre si, pelo teste de Tukey ao nível de $1 \%$ de \\
significância. ${ }^{2}$ Médias seguidas da mesma letra na coluna não diferem entre si, pelo teste de Tukey ao nível de \\
${ }^{5 \%}$ de significância.
\end{tabular}

Cultura Agronômica, Ilha Solteira, v.24, n.4, p.271-280, 2015 
De acordo com Pereira (1995) teores de sólidos solúveis entre 8 e $12^{\circ}$ Brix e acidez titulável em torno de $0,8 \mathrm{~g}$ de ácido cítrico por $100 \mathrm{~g}$ de polpa são considerados satisfatórios.

A cultivar Paluma apresentou-se com o maior valor de acidez $(0,58)$ entre as cultivares (Tabela 4). Segundo Pereira et al. (2009) em frutos maduros desta cultivar, seu sabor é agradável por consequência do elevado teor de açucares, aproximadamente $10^{\circ}$ Brix e a acidez é equilibrada. A cultivar Pedro Sato apresentou valores da acidez total titulável $(0,43)$ superior e relação SS/AT $(18,18)$ inferior aos observados por Hojo et al. (2007) para a mesma cultivar também podada em março. Vila (2004) relata que para esta cultivar a acidez varia de 0,2 a 0,9 $\mathrm{g}$ de ácido cítrico por $100 \mathrm{~g}$ de polpa, atribuindo sabor moderado e boa aceitação para o consumo in natura, estando, portanto esta cultivar dentro destes limites, nas condições deste estudo.

Os frutos da cultivar Sassaoka (Tabela 4) apresentaram o menor valor de acidez $(0,39)$ e a maior relação SS/AT $(20,15)$, porém não diferiu da cultivar Pedro Sato com acidez de 0,43 $\mathrm{g}$ de ácido cítrico por $100 \mathrm{~g}$ de amostra e 18,18 para a relação SST/ATT. Pereira e Nachtigal (2009), relataram que a cultivar Sassaoka produz frutos de sabor leve. A cultivar Século XXI apresentou valores para acidez $(0,49)$ semelhante ao de 0,474 gramas de ácido cítrico por 100 g de polpa relatados por Pereira e Nachtigal (2009).

Observa-se na Tabela 4 que a cultivar Sassaoka produziu frutos com a maior relação SS/AT (20,15), porém não diferiu dos frutos da cultivar Pedro Sato $(18,10)$. Da mesma forma estes últimos não diferiram dos valores encontrados para frutos da cultivar Século XXI $(15,33)$. Já a cultivar Paluma produziu frutos com a menor relação SS/AT $(13,94)$, não diferindo da cultivar Século XXI.

Pereira et al. (2003) relatam que os frutos da cultivar Século XXI apresentam teores de sólidos solúveis próximos a $10^{\circ}$ Brix, considerados como padrão, e acidez titulável de $0,474 \mathrm{~g}$ de ácido cítrico por $100 \mathrm{~g}$ de polpa, o que resulta numa relação SS/AT próximo a 20,0 $(18,6)$, que confere aos frutos sabor bastante adocicado.

As características químicas avaliadas definem a qualidade do fruto de goiabeira. Os teores de sólidos solúveis (SS) proporcionam melhor sabor e maior rendimento na elaboração de produtos industrializados; a acidez titulável (AT) é utilizada na classificação da fruta pelo sabor; a relação SS/AT, indica o índice de maturação da goiaba (LIMA et al., 2002).

De acordo com Dias (1983), os atributos físicos e químicos dos frutos da goiabeira variam de acordo com as variedades cultivadas. Gonzaga Neto et al. (1997) relatam ainda que, as características químicas dos frutos variam de acordo com o clima, solo, tratos culturais e estádio de maturação dos frutos, determinando a qualidade destes.

\section{CONCLUSÃO}

Nas condições deste experimento, conclui-se que a massa, o diâmetro longitudinal e transversal dos frutos e os valores para sólidos solúveis totais, acidez total titulável e o índice de maturação (relação SS/AT) não foram alterados com a aplicação de nitrato de potássio

Cultura Agronômica, Ilha Solteira, v.24, n.4, p.271-280, 2015 
após a poda de frutificação para as cultivares estudadas.

\section{REFERÊNCIAS BIBLIOGRÁFICAS}

ARAÚJO, R. C. Produção, qualidade de frutos e teores foliares de nutrientes no maracujazeiro amarelo em resposta à adubação potássica. 2001. $103 \mathrm{f}$. Tese (Doutorado em Fitotecnia) - Universidade Federal de Viçosa, Viçosa, 2001.

BARROS, P. G.; CUNHA, G. A. P.; REINHARDT, D. H.; FONSECA, N.; BARBOSA, N. M. L. Efeito do nitrato de potássio na floração e frutificação de mangueiras (Mangifera indica L.) cv. Tommy Atkins no Sudoeste da Bahia. Revista Brasileira de Fruticultura, Cruz das Almas, v. 20, n. 2, p.188-194, 1998.

CALDEIRA, M. L. Indução química de florescimento em manga. IN: SIMPÓSIO SOBRE MANGICULTURA, 2, Jaboticabal, 1989. Anais... Jaboticabal: FUNEP, 1989. p. 157-163.

CENTURION, J. F. Balanço hídrico na região de Ilha Solteira. Científica, Jaboticabal, v. 10, n. 1, p.57-61, 1982.

CHATZIVAGIANNIS, M. A. F. Aplicação de diferentes concentrações de paclobutrazol no florescimento e produção de mangueiras das variedades Bourbon, Palmer e Rosa. 2008. 76 f. Dissertação (Mestrado em Fitotecnia) - Universidade Estadual do Sudoeste da Bahia, Vitória da Conquista, 2008.

DIAS, J. M. M. Estudo da produção e dos atributos físicos e químicos dos frutos de duas variedades de goiabeira (Psidium guajava L.), em Visconde do Rio Branco, Minas Gerais. 1983. 68 f. Dissertação (Mestrado em Fitotecnia) - Universidade Federal de Viçosa, Viçosa, 1983.

EMPRESA BRASILEIRA DE PESQUISA AGROPECUÁRIA - EMBRAPA. Sistema Brasileiro de Classificação de Solos. 2 ed. Rio de Janeiro: Brasília, 2006. 306 p.

FERREIRA, D. F. Sisvar: a computer statistical analysis system. Ciência e Agrotecnologia, Lavras, v. 35, n. 6, p.1039-1042, 2011.

GONZAGA NETO, L.; ABRAMOF, L.; BEZERRA, J. E. F.; PEDROSA, A. C.; SILVA, H. M. Seleção de cultivares de goiabeira (Psidium guajava L.) para consumo ao natural, na Região do Vale do Rio Moxotó, em Ibibmirim-Pernambuco. Revista Brasileira de Fruticultura, Cruz das Almas, v. 9, n. 2, p.63-66, 1987.

GONZAGA NETO, L.; LEODIDO, J. M. C.; SILVA, E. E. G. Raleamento de frutos de goiabeira cv. Rica em Juazeiro-BA, Brasil. Pesquisa Agropecuária Brasileira, Brasília, v. 32, n. 12, p.1281-1286, 1997.

Cultura Agronômica, Ilha Solteira, v.24, n.4, p.271-280, 2015 
HOJO, R. H.; CHALFUN, N. N. J.; HOJO, E. T. D.; VEIGA, C. M. P.; LIMA, L. C. O. Produção e qualidade dos frutos da goiabeira 'Pedro Sato' submetida a diferentes épocas de poda. Pesquisa Agropecuária Brasileira, Brasília, v. 42, n. 3, p.357-362, 2007.

INSTITUTO ADOLFO LUTZ. Normas analíticas do Instituto Adolfo Lutz. I - métodos químicos e físicos para análise de alimentos. 3.ed. São Paulo: IMESP, 1985. 533 p.

LIMA, M. A. C.; ASSIS, J. S.; GONZAGA NETO, L. Caracterização dos frutos de goiabeira e seleção de cultivares na região do Submédio São Francisco. Revista Brasileira de Fruticultura, Jaboticabal, v. 24, n. 1, p.273-276, 2002.

KAVATI, R. Cultivares. In: SIMPÓSIO BRASILEIRO SOBRE A CULTURA DA GOIABEIRA, 1., 1997, Jaboticabal. Anais... Jaboticabal: FUNEP-GOIABRAS, 1997. p. 116.

MANICA, I.; ICUMA, I. M.; JUNQUEIRA, N. T. V.; SALVADOR, J. O.; MOREIRA, A.; MALAVOLTA, E. Fruticultura tropical 6: goiaba. Porto Alegre: Cinco Continentes, 2000. $374 \mathrm{p}$.

MEDINA, J. C. Goiaba: cultura, matéria-prima, processamento e aspectos econômicos. 2.ed. rev. ampl. Campinas: ITAL, 1988. 120 p. (Série Frutas Tropicais, 6)

NUÑEZ-ELISEA, R.; CALDEIRA, M. L. Adelanto de la floración e cosecha em mango 'Haden' com aspersiones de nitrato de amônio. In: CONGRESSO BRASILEIRO DE FRUTICULTURA, 9., 1987, Campinas. Anais... Campinas: SBF, 1987. v. 2, p.7-561.

PAL, R. N.; CHADKA, K. L.; RAO, M. R. K. Effect of different plant growth regulators and other chemicals on flowering behaviour of mango. Indian Journal Horticultural, Nova Delhi, v. 41, p.8-15, 1984.

PEREIRA, F. M. Cultura da goiabeira. Jaboticabal: FUNEP, 1995. 47 p.

PEREIRA, F. M.; CARVALHO, C. A.; NACHTIGAL, J. C. Século XXI: nova cultivar de goiabeira de dupla finalidade. Revista Brasileira de Fruticultura, Jaboticabal, v. 25, n. 3, p.498-500, 2003.

PEREIRA, F. M.; NACHTIGAL, J. C. Melhoramento da goiabeira. In: ROZANE, D. E.; COUTO, F. A. d`A. (Ed.). Cultura da goiabeira: tecnologia e mercado. Viçosa: UFV, 2003. cap. 4 , p. 53-78.

PEREIRA, F. M.; NACHTIGAL, J. C. Melhoramento genético da goiabeira. In: NATALE, W.; ROZANE, D. E.; SOUZA, H. A.; AMORIM, A. A. (Org.). Cultura da goiaba: do plantio à comercialização. Jaboticabal: FCAV/Unesp, 2009. v. 2, cap. 15, p.371-398.

Cultura Agronômica, Ilha Solteira, v.24, n.4, p.271-280, 2015 
PESSOA, W. R. L. S.; LOPES, A. L.; COSTA, V. S. O.; OLIVEIRA, S. M. A. Efeito do tratamento hidrotérmico associado a indutores de resistência em pós-colheita de goiaba. Caatinga, Mossoró, v. 22, n. 1, p.85-90, 2009. Disponível em: http://caatinga.ufersa.edu.br/index.php/sistema/article/viewFile/176/512. Acesso em: 18 ago. 2010.

POMMER, C. V.; MURAKAMI, K. R. N.; WATLINGTON, F. Goiaba no mundo. O Agronômico, Campinas, v. 58 , n. $1 / 2$, p. 22-26, 2006. (Boletim Técnico do Instituto Agronômico. Série Técnica Apta)

RAIJ, B. V.; CANTARELLA, H.; QUAGGIO, J. A.; FURLANI, A. M. C. Recomendações de adubação e calagem para o Estado de São Paulo. 2 ed. Campinas: Instituto Agronômico - IAC, 1996. 285 p. (Boletim Técnico, 100)

SILVA, R. A.; CAVALCANTE, L. F.; HOLANDA, J. S.; PEREIRA, W. E.; MOURA, M. F.; FERREIRA NETO, M. Qualidade de frutos do coqueiro-anão verde fertirrigado com nitrogênio e potássio. Revista Brasileira de Fruticultura, Jaboticabal, v. 28, n. 2, p.310-313, 2006.

VALENTE, J. P.; DONADIO, L. C. Mango induction by $\mathrm{KNO}_{3}$ and ethephon. In: INTERNATIONAL SYMPOSIUM ON FRUITS, 1., 1993, Vitória. Abstracts... Vitória: EMCAPA, 1993. p. 51.

VILA, M. T. R. Qualidade pós-colheita de goiaba 'Pedro Sato' armazenadas sob refrigeração e atmosfera modificada por biofilme de fécula de mandioca. 2004. 66 f. Dissertação (Mestrado em Ciência dos Alimentos) - Universidade Federal de Lavras, Lavras, 2004. 